\title{
Hybrid Flow-Shop Scheduling Problem Based on Genetic Algorithm
}

\author{
Zhang Rong
}

\author{
Department of Mechanical Engineering, Dalian Vocational \& Technical College, Dalian, Liaoning, \\ 116037,China \\ Lzhch11993@sina.com
}

Keywords: Job shop scheduling problem; Material flow; Genetic algorithm; Hybrid flow-shop scheduling problem

\begin{abstract}
In order to solve the job shop scheduling problem which includes disordered material flow and lopsided load of equipment, the thesis has done some research on how to apply in genetic algorithm on hybrid flow-shop scheduling problem. And the thesis also has illustrated the method of realization from a company of producing engine of automobile.
\end{abstract}

\section{Introduction}

With the gradual expansion of production scale, more and more complex, the demand for resources increased sharply, the market competition is more and more intense, the enterprise management and production process monitoring have put forward higher requirements. Many enterprises in the mechanical processing plant in the production scheduling and management tools, still remain in the manual management stage. In order to ensure the production of efficient and stable operation, in order to obtain the greatest economic benefits, such as genetic algorithms to be advanced optimization technology into the production process monitoring [1].

Genetic Algorithms as a global stochastic search algorithm, which is based on natural selection and natural genetic mechanism, simulates the evolution of biology from low level to high level in nature. The main advantage of Genetic Algorithms is that the optimal solution is independent of the gradient information , For complex optimization problems, only need to use the selection, crossover, mutation of the three kinds of genetic operators can be optimized solution.

Hybrid shop scheduling problem is a generalization of the traditional flow shop scheduling problem. It involves three-dimensionality of tasks, resources and time. It is very difficult to establish precise mathematical model. This problem has been proved to be an non-deterministic polynomial problem, and it is difficult to rely on artificial good scheduling in the production process. Therefore, it is necessary to study the scheduling problem of the mixed-flow shop and make the automatic sorting.

\section{Hybrid Flow-shop Scheduling Problem}

Problem Model. Hybrid flow-shop scheduling problem is an extension of the flow shop scheduling problem. The problem can be described as follows, $\mathrm{N}$ pieces in the assembly line are processed on the $\mathrm{M}$ stage. Each stage has at least one machine and at least one stage there are multiple machines, and the same stage of the processing performance of the same machine. In each stage of the workpiece to complete a process, the workpiece of each process can be in the corresponding stage of any one machine on the processing. Known the processing time of each process of the workpiece, to determine the order of all the workpiece and the distribution of machines on each stage, making the minimum scheduling index.

Problem Example. A car engine plant processing plant to process 12 parts, each workpiece has turning, planning and grinding three processes, the existing three lathes(M1, M2, M3 complete the process 1), two planers (M4, M5 complete the process 2), four grinders(M6, M7, M8, M9 complete the process 3 ), each machine's processing capacity is different, the specific processing time shown in Table 1 [2]. 
Table 1 Workpiece machining time on the machine

\begin{tabular}{c|ccc|cc|cccc}
\hline \multirow{2}{*}{$\begin{array}{l}\text { Workpiece } \\
\text { number }\end{array}$} & \multicolumn{3}{|c|}{ process 1 } & \multicolumn{3}{c|}{ process } & \multicolumn{5}{c}{ process 3 } \\
\cline { 2 - 10 } & M1 & M2 & M3 & M4 & M5 & M6 & M7 & M8 & M9 \\
\hline 1 & 2 & 2 & 3 & 4 & 5 & 2 & 3 & 2 & 3 \\
2 & 4 & 5 & 4 & 3 & 4 & 3 & 4 & 5 & 4 \\
3 & 6 & 5 & 4 & 4 & 2 & 3 & 4 & 2 & 5 \\
4 & 4 & 3 & 4 & 6 & 5 & 3 & 6 & 5 & 8 \\
5 & 4 & 5 & 3 & 3 & 1 & 3 & 4 & 6 & 5 \\
6 & 6 & 5 & 4 & 2 & 3 & 4 & 3 & 9 & 5 \\
7 & 5 & 2 & 4 & 4 & 6 & 3 & 4 & 3 & 5 \\
8 & 3 & 5 & 4 & 7 & 5 & 3 & 3 & 6 & 4 \\
9 & 2 & 5 & 4 & 1 & 2 & 7 & 8 & 6 & 5 \\
10 & 3 & 6 & 4 & 3 & 4 & 4 & 8 & 6 & 7 \\
11 & 5 & 2 & 4 & 3 & 5 & 6 & 7 & 6 & 5 \\
12 & 6 & 5 & 4 & 5 & 4 & 3 & 4 & 7 & 5 \\
\hline
\end{tabular}

\section{Coding Design of Genetic Algorithm}

For hybrid flow-shop scheduling problem scheduling problem, each stage must be resolved to sort the workpiece and the distribution of parallel machines [3] [4]. In this paper, a simple encoding method is applied, The $m$ sub-permutations can be combined to form a chromosome, wherein each sub-arrangement is a random complete permutation of all artifacts, and is divided into $M_{i}$ segments by $M_{i}-1$ separators "*", each sub-segment represents the order of workpiece machining on a parallel machine at that stage. Obviously, repeating the above chromosome generation process several times can generate a number of different scheduling schemes, and then constitute the genetic algorithm population.

For example, the hybrid flow-shop scheduling problem of an automotive engine plant can be solved by chromosomes [1 $3711 * 510912 * 4628 * * 157431011 * 682912 * * 15711$ * $43 * 612 * 89210$ ], the meaning of the representative are shown in the following.

The machine 1 sequentially processes the workpieces $1,3,7,11$; the machine 2 sequentially processes the workpieces $5,10,9,12$; the machine 3 sequentially processes the workpieces $4,6,2$, 8 ; the machine 4 sequentially processes the workpieces $1,5,7,4,3,10,11$; the machine 5 sequentially processes the workpieces $6,8,2,9,12$; the machine 6 sequentially processes the workpieces $1,5,7,11$; the machine 7 sequentially processes the workpieces 4,3; the machine 8 sequentially processes the workpieces 6,12 ; the machine 9 sequentially processes the workpieces 8 , 9, 2, 10.

\section{Experimental Results}

The main parameters of the experiment are shown in Table 2, through the parameters of the scheduling of the above example of genetic algorithm operation, the results shown in Table 3, the result is the iteration algebra and the iteration time used to get the optimal solution in 10 operations, in addition, the optimal chromosome was obtained, [9 $1063 * 1151 * 724128 * * 9752163$ * $11104128 * * 751068 * 4 * 9212 * 1113$ ]. According to the chromosome, the optimal scheduling time is 29 . Figure 1 shows the optimal gantt chart for the processing plant scheduling of the automobile engine plant [5]. 
Table 2 Algorithm Parameters

\begin{tabular}{|c|c|c|c|c|c|c|c|c|c|c|c|}
\hline $\begin{array}{r}\text { number of } \\
\text { experiments }\end{array}$ & \multicolumn{2}{|c|}{$\begin{array}{l}\text { population } \\
\text { scale }\end{array}$} & \multicolumn{2}{|c|}{$\begin{array}{l}\text { iteration } \\
\text { frequency }\end{array}$} & \multicolumn{2}{|c|}{$\begin{array}{c}\text { cross } \\
\text { Probability }\end{array}$} & $\begin{array}{c}\text { variation } \\
\text { Probability }\end{array}$ & \multicolumn{2}{|c|}{$\begin{array}{c}\text { cross } \\
\text { frequency }\end{array}$} & \multicolumn{2}{|c|}{$\begin{array}{l}\text { variation } \\
\text { frequency }\end{array}$} \\
\hline 100 & & & 35 & & 0.9 & & 0.005 & & 100 & & 100 \\
\hline \multicolumn{12}{|c|}{ Table 3 Experimental results } \\
\hline \multicolumn{2}{|c|}{ frequency } & 1 & 2 & 3 & 4 & 5 & 6 & 7 & 8 & 9 & 10 \\
\hline \multicolumn{2}{|c|}{ Iteration frequency } & 42 & 30 & 47 & 33 & 37 & 41 & 39 & 37 & 47 & 54 \\
\hline \multicolumn{2}{|c|}{ Convergence time/s } & 4.12 & 2.99 & 4.67 & 3.25 & 3.7 & 4.09 & .00 & 3.67 & 4.65 & 5.34 \\
\hline
\end{tabular}

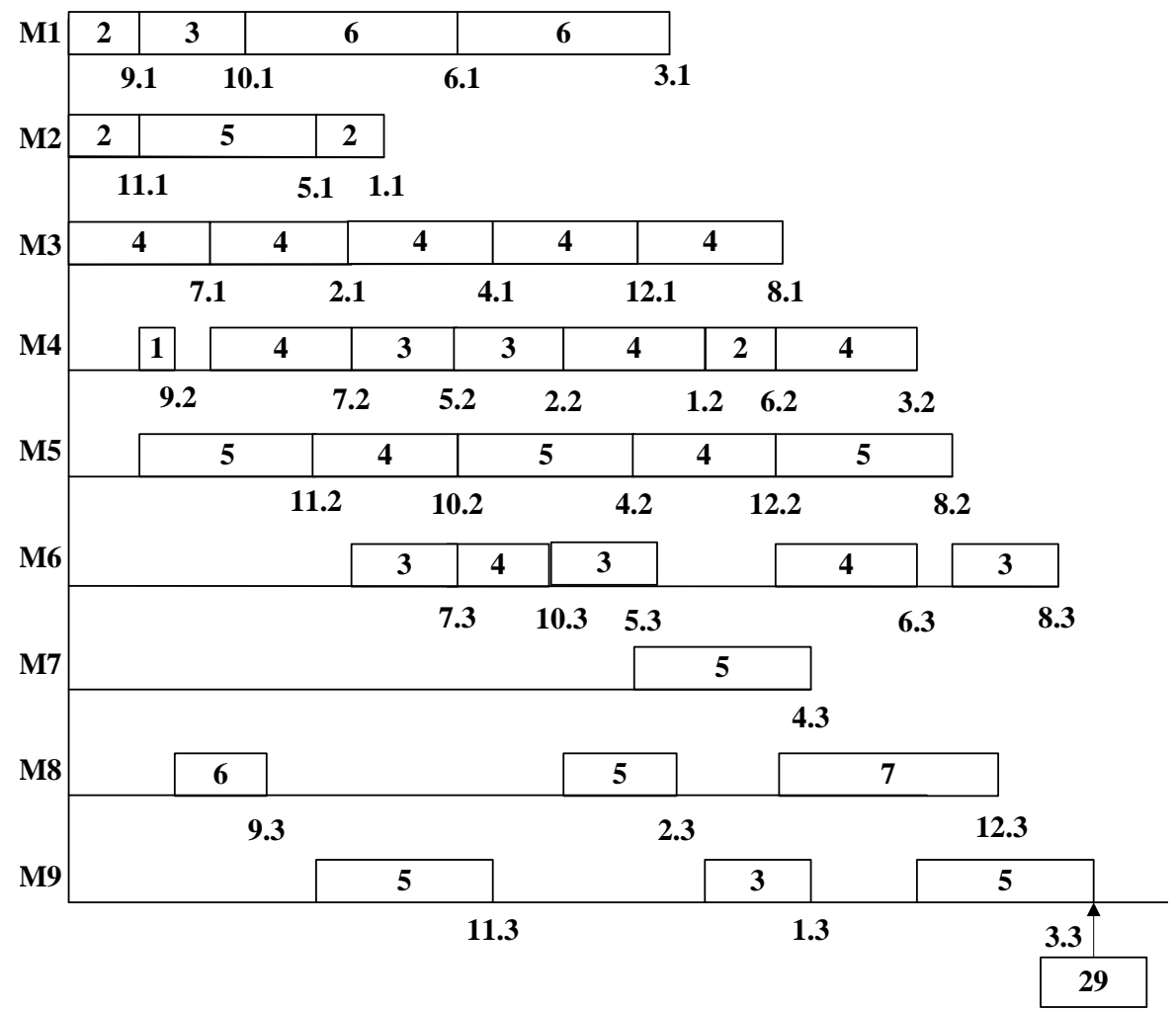

Fig 1 the optimal gantt chart for the processing plant scheduling of the automobile engine plant

\section{Conclusion}

In this paper, genetic algorithm is applied to solve complicated shop floor scheduling problem. The paper is divided into several chapters. In the introduction, it states the significance, recent actuality and research methods of job shop scheduling problem. Then the succeed the following chapters include the presentation of genetic algorithm , the typical descriptions of job shop, flow shop, machine scheduling earliness-tardiness and virtual scheduling and its research strategy [6-7]. The performance is compared when using different genetic algorithm coding mode. The simulation scheduling results of several samples show genetic algorithm 's feasibility, reliability and validity in solving job shop scheduling problems. The last an example of hybrid flow scheduling in an automobile engine plant is given to show that the genetic algorithm can get the optimal solution of the problem in a few seconds. So in the actual production of the enterprise application, the method can greatly improve the production scheduling process of resource allocation and processing time [8-9].

\section{References}

[1] Yungao Wu. Job Shop Scheduling Based on Genetic Algorithm and Its Application (Master 
Thesis). Zhejiang University of Technology. 2002.

[2] Zhentong Chen. Research and Application of Job Shop Scheduling Problem Based on Improved Genetic Algorithm(Master Thesis). Dalian: Dalian University of Technology, 2007.

[3] Wang Ling. Job Shop Scheduling and Genetic Algorithm [M]. Beijing: Qinghua University Press, 2003.

[4] Xiaoping Wang, Liming Cao. Genetic Algorithm-Theory, Application and Software Realization [M]. Xi'an: Xi'an Jiaotong University Press, 2002

[5] Hengyong Tang, Chuanli Zhao. Sorting Introduction [M]. Beijing: Science Press.2002.

[6] Garey M R,Johnson D S, Sethi R. The complexity of flow shop jobsop scheduling [J]. M Athematics of Operation Research,1976, 1:17 29.

[7] Fajendran C, Ziegler H. An efficient heuristic for scheduling in a flow shop to minimize to talweighted flow time of jobs[J]. European Journal of Operational Research,1997,103:129 138.

[8]W anc C, Chu C, Proth J M. Heuristic approaches for $\mathrm{n} / \mathrm{m} / \mathrm{F} / \Sigma \mathrm{Ci}$ scheduling problems[J]. European Journal of Operational Research, 1997, 96: 636 644.

[9] Framinan J.M, Leisten R. An efficient constructive heuristic for flow time minimization in permutation flow shops [J]. OM EGA,2003,31:311 317. 